\title{
Analytical Study of Viscosity Effects on Waterflooding Performance to Predict Oil Recovery in a Linear System
}

\author{
Abbas Mamudu ${ }^{1 *}$, Olafuyi Olalekan ${ }^{2}$ and Giegbefumwen Peter Uyi ${ }^{3}$ \\ University of Benin, Benin City, Nigeria
}

\begin{abstract}
Waterflood displacement efficiency is affected by the viscosity ratio of the displaced to the displacing fluid. Therefore, the oil recovered in a water flooding process is largely determined by the viscosity ratio.

This paper presents a quantitative analysis of the viscosity effects on oil recovery in a linear system using Buckley-Leverett equation and other related mathematical models to simulate the effects on two stages: Case one, when the viscosity of the displaced fluid was varied from $5 c p$ to $300 c p$ and that of the displacing fluid remained constant at $1 c p$. And case two, when the viscosity of the displaced fluid was at $2 c p$ and that of the displacing fluid varied from $2 c p$ to $10 c p$ with the assumption of miscibility between the viscous water and the interstitial water or previously injected water. With the aid of the fractional flow curves, the value for the average water saturations, $\bar{S}_{w}$ behind the shock front associated with each change in the viscosity ratio was obtained and the corresponding recoveries were predicted.
\end{abstract}

The results show appreciable recovery at a viscosity ratio as high as 100 , however, the S-shape of the fractional flow curve diminishes with increasing viscosity ratio. At $200 \mathrm{cp}$ and above, the S-shape totally disappears. Viscous fluid appreciably improves oil recovery particularly in reservoirs containing viscous oil. The difference between $S_{w f}$ and $\bar{S}_{w}$ is constant at various viscosity ratios till the disappearance of the S-shape of the fractional flow curve. Recovery increases with decreasing viscosity ratio and decreases with increasing viscosity ratio. At a very low viscosity ratio, $\frac{\mu_{o}}{\mu_{w}}$ of $0.4, \bar{S}_{w}$ equals the end point water saturation, and this gives the highest possible oil recovery (the optimum). The oil produced, $\mathrm{N}_{p}$ and the average water saturation, $\bar{S}_{w}$ in an immiscible displacement system are linearly related.

Keywords: Average water saturation; Buckley-Leverett equation; Fractional flow curve; Fractional flow equation; Oil Initially-in-place equation; Oil produced; Optimum recovery; S-shape; Viscosity ratio and OIP- Oil in place

\section{Introduction}

During waterflooding, the objective is to displace oil successfully. However, achieving this seems difficult without proper analysis. Frontal advance theory provides the answer to this in 1-D. It's been observed over time that the oil recovered in an immiscible displacement system is largely a function of the viscosity ratio. This is due to the fact that the waterflood displacement efficiency is affected by the viscosity ratio of the displaced to the displacing fluid [1]. Therefore, an analytical study of viscosity ratio alteration to avoid unfavorable viscosity ratios and to predict recoveries correspondingly becomes of paramount importance. It should also be noted that an important aspect of any EOR process is the effectiveness of the process fluids in removing oil from the rock pores at the microscopic scale [2]. Microscopic displacement efficiency, $E_{D}$ largely determines the success or failure of a process. For crude oil, $E_{D}$ is reflected in the magnitude of $S_{\text {or }}$ (residual oil saturation) [2-4] whose mobilization is the primary aim of waterflooding. The volume of oil displaced during a viscous waterflood is determined by computing the average water saturation in the system at various points in time as done for waterflooding calculations [5-10]. However, the assumption that the viscous water is miscible with the interstitial water or previously injected water was upheld throughout this study.

In 1942, Buckely and Leverett presented what is recognized as the basic equation for describing immiscible displacement in one dimension $[11,12]$. For water displacing oil, the equation determines the velocity of a plane of a constant water saturation Travelling through a linear system. The equation is derived based on developing a material balance for the displacing fluid as it flows through any element in the given media [11-13]. This well-established theory called frontal displacement theory is very useful in finding solutions to problems when is shown that $E_{D}$ will continually increase with increasing water saturation in the reservoir by developing an approach for determining the increase in average water saturation in the swept area as a function of the cumulative water injected (or injection time) or when there is increase in oil produced at different increases in viscosity ratio by developing an approach for determining the increase in average water saturation in the swept area as a function of the viscosity ratio alteration. The later is the area of interest in this paper. This classic theory consists of two equations: Fractional flow equation and Frontal advance equation.

The development of the fractional flow equation is attributed to leverett. For two immiscible fluids, oil and water, the fractional flow of water, $f_{w}$ ( or any immiscible displacing fluid) is defined as the water flow rate divided by the total flow rate (Figure 1).

Thomas, Mahoney and Winter pointed out that in determining the suitability of a candidate reservoir for waterflooding The following

*Corresponding author: Abbas Mamudu, Research Assistant, University of Benin, Benin City, Nigeria, Tel/Fax: +2348039351412; E-mail: abbasagim@yahoo.com

Received February 18, 2015; Accepted April 14, 2015; Published April 21, 2015

Citation: Mamudu A, Olalekan O, Uyi PG (2015) Analytical Study of Viscosity Effects on Waterflooding Performance to Predict Oil Recovery in a Linear System. J Pet Environ Biotechnol 6: 221. doi:10.4172/2157-7463.1000221

Copyright: (c) 2015 Mamudu A, et al. This is an open-access article distributed under the terms of the Creative Commons Attribution License, which permits unrestricted use, distribution, and reproduction in any medium, provided the original author and source are credited. 


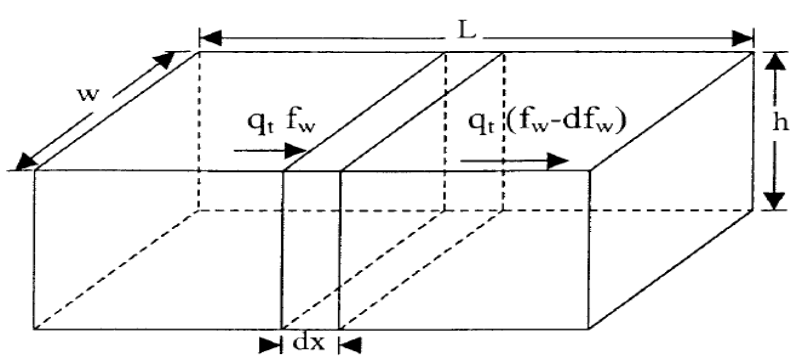

Figure 1: Water Flow Through A linear Deferential Elemental.

characteristics must be considered:

- $\quad$ Reservoir geometry

- $\quad$ Fluid properties

- Reservoir depth

- $\quad$ Lithology and rock properties

- Fluid saturation.

This analytical study was done assuming that all the above characteristics are favorable and using selected relative permeability data. The data must be available to construct the fractional flow curves. It should be noted that relative permeabilities are measured in the laboratory under the diffuse flow condition. This normally results from displacing one fluid by another in thin core plugs at high flow rates [13]. As such, the laboratory or rock relative permeabilities must be regarded as point relative permeabilities which are functions of the point water saturation in the reservoir. During the analysis, with the aid of the relative permeability data, several fractional flow curves were constructed at different viscosity ratios. The corresponding values of the average water saturation behind the shock front, $\bar{S}_{w}$ were obtained to predict the corresponding oil recoveries. All the required reservoir parameters were assumed with the shock front at breakthrough. The models used include Buckley-Leverett equation, fractional flow equation and oil in place equation.

In (2011), Ghosh and Alshalabi did a similar research termed "Solvent Induced Oil Viscosity Reduction and Its Effect On Waterflood Recovery Efficiency". While Fried in 1955, worked on "Effect of Oil Viscosity On The Recovery Of Oil by Water Flooding".

The main objectives of this study are to analyze the effects of viscosity on immiscible displacement systems to know the most favorable viscosity ratios at which optimum recoveries could be predicted, and to know the effects of its alterations on oil recovery, average water saturation behind the shock front, shock front saturation and the fraction flow curve itself.

\section{Frontal Advance and Related Equations}

Frontal advance theory provides the answers to many challenges in immiscible displacement systems. The equations derived from this theory and that of OIIP were used in this present study based on the following assumptions:

- Rate is constant

- The system is linear

- The water in the rock is initially at interstitial water saturation

- The rock is a uniform horizontal reservoir
- Porosity is constant

- Permeability is constant

- The injected viscous water is miscible with the interstitial water or previously injected water

- The displacement process is at breakthrough

- Gravity forces are negligible

- Capillary forces are negligible

- The fluids are incompressible

- The reservoir is rectangular

\section{Buckley -Leverett equation}

This equation, called the frontal advance or Buckley-Leverett equation was derived by Willhite as [8].

$$
\frac{d S_{S_{w}}}{d t}=\frac{q_{T}}{A \varnothing}\left(\frac{\partial f_{w}}{\partial S_{w}}\right)_{S=S_{w}}
$$

Where $x_{S_{w}}=$ location of water saturation, $S_{W}$ measured from $x$ $=0, \mathrm{~A}=$ cross sectional area, $\varnothing=$ porosity, $q_{T}=$ injection rate, $f_{w}=$ fractional flow of water and $t=$ time from the beginning of injection.

Eqn (1) could be integrated and expressed in terms of the distance travelled as

$$
\left.x\right|_{S_{w}}=\left.\frac{q_{T} t}{A \varnothing} \frac{d f_{w}}{d S_{w}}\right|_{S_{w}}
$$

And finally, in terms of average water saturation as

$$
\bar{S}_{w}=S_{w f}+\left(1-\left.f_{w}\right|_{S_{w f}}\right)\left(1 /\left.\frac{d f_{w}}{d S_{w}}\right|_{S_{w f}}\right)
$$

\section{Fractional flow equation}

As developed by Leverett, for two immiscible fluids, oil and water, the water flow rate is given as

$$
f_{w}=\frac{q_{w}}{q_{T}}=q_{w} / q_{w}+q_{o}
$$

where $\mathrm{f}_{\mathrm{w}}=$ fraction of water in the flowing stream, i,e., water cut, $q_{T}$ = total flow rate, $q_{w}=$ water flow rate and $q_{o}=$ oil flow rate.

This effort of Leverett assists in determining the water cut at any given point in time.

\section{Oil In Place Equation (OIP)}

The volume of oil displaced in a water flooding project is determined by computing the average water saturation in the swept zone or behind the shock front. When the initial oil saturation is $1-S_{i w}$, the oil displaced is given as

$$
N_{p}=\frac{A \varnothing L\left(\bar{S}_{w}-S_{i w}\right)}{B_{o}}
$$

Where $N_{p}=$ oil produced, $A=$ reser reservoir length, $\varnothing=$ reservoir porosity, ${ }^{w}=$ average water saturation in the swept zone and $S_{i w}=$ interstitial water saturation. 
The effects of viscosity ratio on oil recovery were analyzed using the above mathematical equations at breakthrough, $x_{f}=L$.

At breakthrough, Eqn (3) becomes

$$
\bar{S}_{w_{b t}}=S_{w_{b t}}+\left(1-\left.f_{w}\right|_{S_{w_{b}}}\right)\left(1 /\left.\frac{d f_{w}}{d S_{w}}\right|_{S_{w b t}}\right)
$$

and Eqn (5) becomes

$$
N_{p_{b t}}=\frac{A \varnothing L\left(\bar{S}_{w}-S_{i w}\right)}{B_{o}}
$$

The following rock and fluid parameters were assumed for this analysis.

$$
\begin{aligned}
h & =40 \mathrm{ft}, \varnothing=0.18, B_{o}=1.3 \mathrm{RB} / \mathrm{STB}, S_{i w}=0.20, L=2000 \mathrm{ft}, \\
\text { and } A & =25000 \mathrm{ft}^{2}
\end{aligned}
$$

To simulate the effects of the viscosity ratio, we considered two cases. Case one: Where we considered oil with increasing viscosity, and case two: Where we considered viscous water (viscous fluid) (Figure 2).

Case 1: With the viscosity of water at $1 c p$, we varied that of oil from $5 c p$ to $300 c p$. Between $5 c p$ and $50 c p$, we took a step of $5 c p$ in the viscosity of oil to initiate viscosity ratio alteration which was enough to provide us with fractional flow curves with distinct features. However, above 50cp, the changes in the step became so minimal that they were initiated based on the information required from the curves. Precisely, $50 c p$ and $100 c p$ were the changes initiated. For each change made in the viscosity ratio, the corresponding value of the average water saturation was determined using eqn (6) with the aid of the fractional flow curve accordingly constructed. But it could still be read directly from the curve. This value is then imputed in eqn (2.7) to predict the resulting recovery. The constructed fractional flow curves are depicted in Figure 3a-n. Visual Basin. Net was the program used to program the equations for the simulation process.

Case 2: Here, we considered viscous water. The viscosity of the oil was kept constant at $2 c p$ and that of the viscous water (fluid) varied from $2 c p$ to $10 c p$. The step here is $2 c p$ and the same calculations as done in case 1 were repeated. The constructed graphs were presented Figure $3 \mathrm{a}-\mathrm{c}$ respectively.

\section{Results and Discussion}

Figure 2 shows the results of the predicted oil recoveries at different viscosity ratios. It shows the oil recovery as a function of the viscosity ratio. It reveals that the recovery decreases with increasing viscosity ratio. A very swift decline occurs in the recovery between 1 and 100, indicating the extent of the effect the viscosity ratio has on the average water saturation in the swept zone within this range of viscosity ratio. As it increases further, the corresponding change in the recovery becomes relatively less such that maintaining a viscosity ratio of 100 , 200 and 300 gives a loss of recovery of $263 \times 10^{4} S T B, 245 \times 10^{4} S T B$ and $102 \times 10^{3} S T B$ respectively. At a viscosity ratio of 300 , it gives a recovery of $693 \times 10^{3}$ STB.

Figure 3a-1 show the fractional flow profiles with the constructed tangent for each of the value of the viscosity ratio considered. Figure 3 a shows the profile when the viscosity ratio is 1 . The s-shape of the fractional flow is very distinct, and at $f_{w 1}=1, \bar{S}_{w}=0.73$. It shows that the values of the fractional flow at the shock front, $\left.f_{w}\right|_{S_{w f}}$ and the shock front saturation, $S_{w f}$ are 0.88 and 0.66 respectively.

Figure 2 shows the graph of oil recovery versus increasing viscosity ratio.

Figure $3 \mathrm{~b}$ shows the fractional flow profile when the viscosity ratio is 5. At $f_{w 1}=1, \bar{S}_{w}=0.61$ and it also shows that the values of the fractional flow at the shock front, $\left.f_{w}\right|_{S_{w f}}$ and the shock front saturation, $S_{w f}$ are 0.8 and 0.53 respectively. This shows that the average water saturation decreases with increasing viscosity ratio. The respective values of the viscosity ratio, average water saturation, fractional flow at the displacement front and shock front saturation for all the constructed fractional flow curves are presented in Table 1. The graphs from which these values are picked are in Figures 3a-l. They show that the s-s shape of the fractional flow curve gets distorted with increasing viscosity ratio, which greatly affect recovery.

Figures 3l-n, show the effect of high viscosity ratio on the nature of the fractional flow curve and recovery. Figure $3 \mathrm{~m}$ shows that at 100 the s-shape of the fractional flow curve is almost entirely distorted; however, oil can still be produced. Beyond this, as shown in Figure $3 \mathrm{~m}$ $\mathrm{n}$, the s-shape is completely distorted. The values of the average water saturation are 0.32 and 0.3 respectively. The recoveries are presented in Figure 2.

Figure $4 \mathrm{a}-\mathrm{c}$ shows the fractional flow profile of viscous water. Though viscosity ratio of $0.2,0.22,0.25,0.29,0.33,0.40,0.50$, and 0.67 were used to construct the fractional flow curves shown in Figure 2.2, However, Figure $3.3 \mathrm{c}$ shows that at a viscosity ratio of less 0.40 under the assumed conditions, no practical significance would be shown on the fractional flow curve because it shows that the average water saturation, $\bar{S}_{w}$ at $f_{w}=1$ is 0.8 , that is, it's equal to the end point water saturation and this gives the highest possible oil recovery (It means that all the movable oil has been produced) as depicted in Figure 3.1. Table 2 shows the selected water saturation and relative permeability data used in this analysis.

Figure 5 shows average water saturation profile. Here, the water saturation is a function of the viscosity ratio. It shows that as the viscosity ratio increases the average water saturation decreases. And it also suffices to say that the response of the average water saturation, $\bar{S}_{w}$ to the viscosity ratio is the same as that of the recovery to it. This is tenably justified in Figure 6 which shows that a linear relationship exists between the two parameters.

Figure 7 shows comparative responses of the average water saturation and the water saturation at the shock front. It shows that

\section{Recovery}

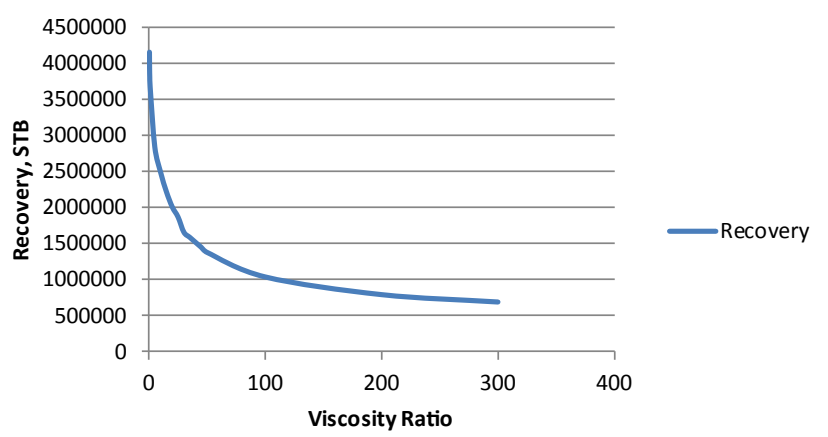

Figure 2: Oil Recovery versus increasing Viscosity Ratio. 
Citation: Mamudu A, Olalekan O, Uyi PG (2015) Analytical Study of Viscosity Effects on Waterflooding Performance to Predict Oil Recovery in a Linear System. J Pet Environ Biotechnol 6: 221. doi:10.4172/2157-7463.1000221

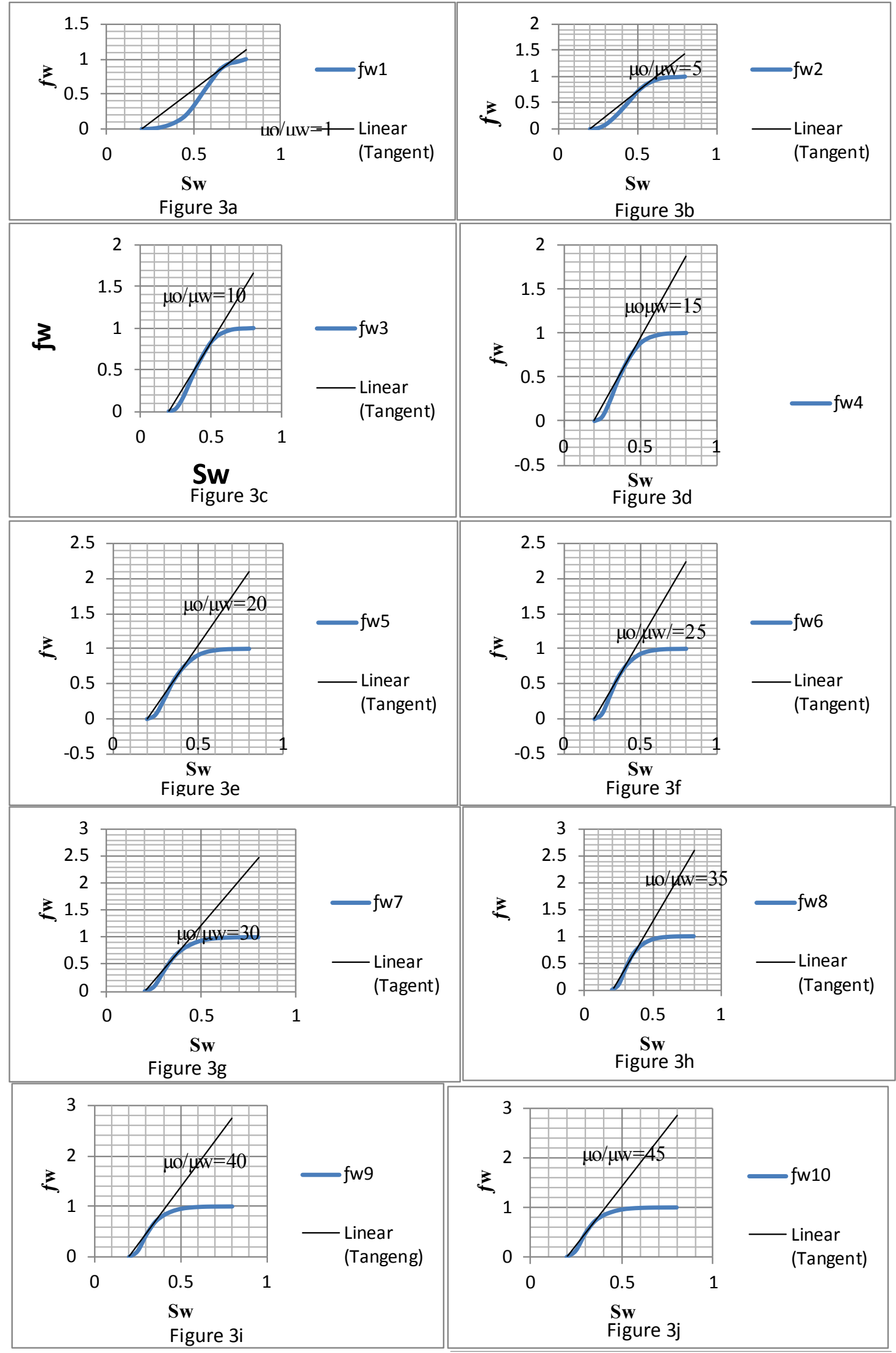




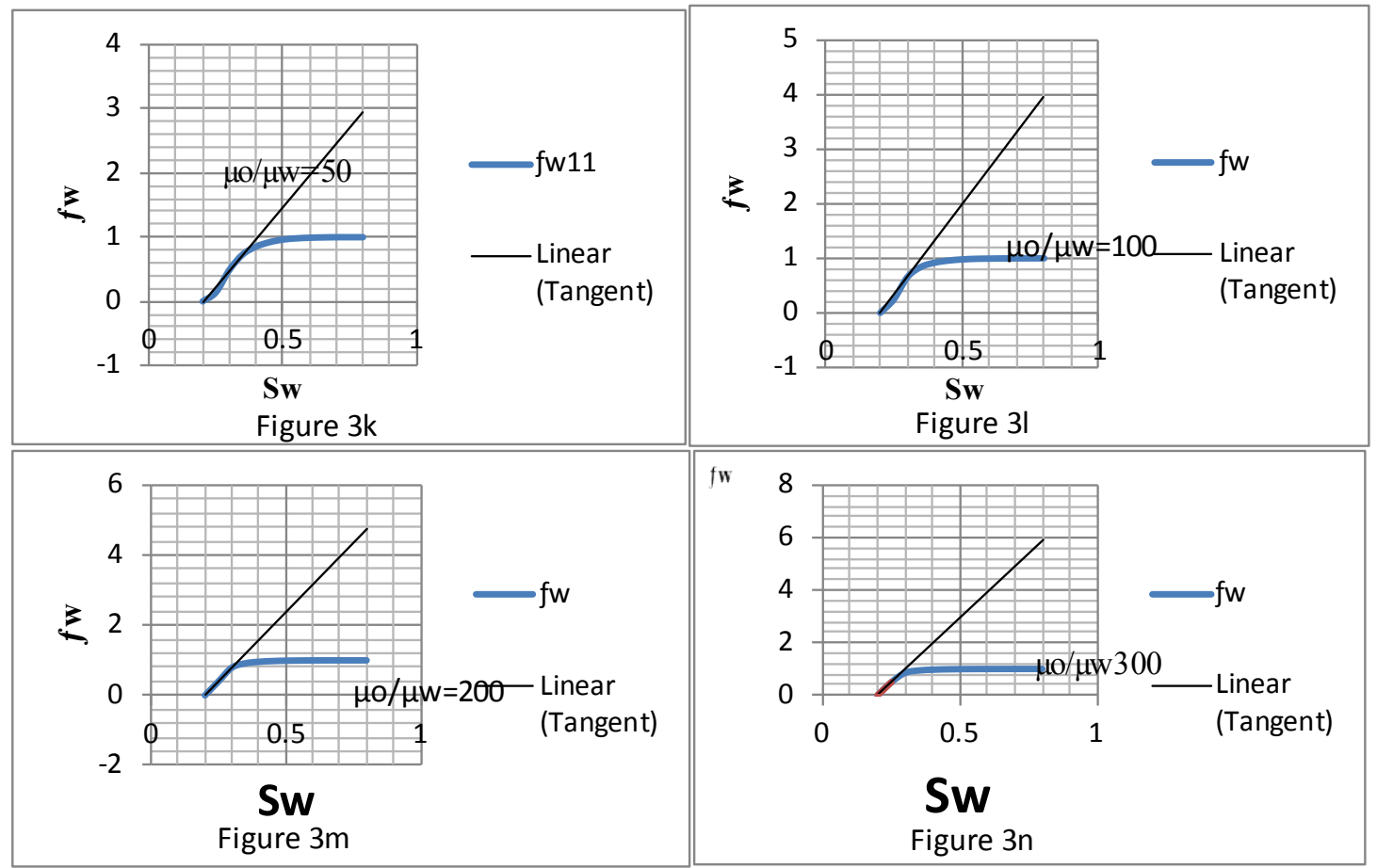

Figure 3a-n: OFractional flow profiles with constructed tangent at different viscosity ratios.

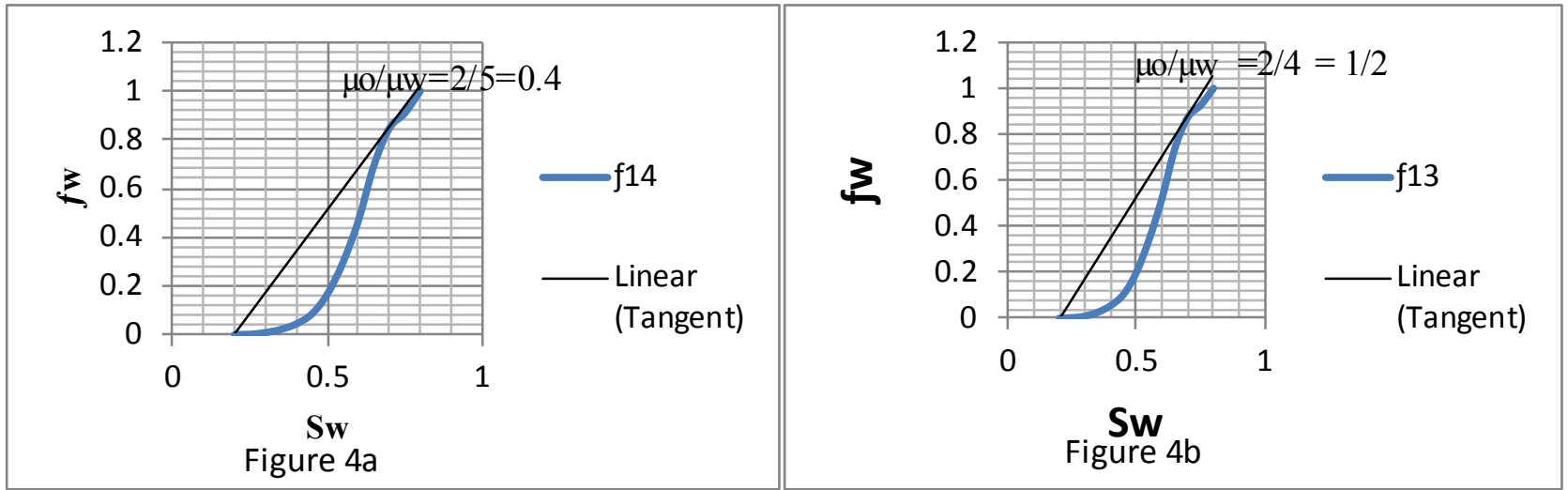

Figure 4a

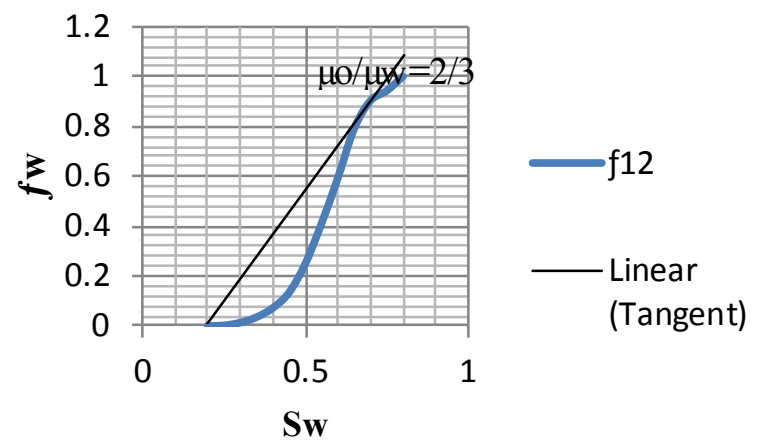

Figure 4c

Figure 4a-c: Fractional flow profiles with constructed tangents at various viscosity ratios of less than 1. 
Citation: Mamudu A, Olalekan O, Uyi PG (2015) Analytical Study of Viscosity Effects on Waterflooding Performance to Predict Oil Recovery in a Linear System. J Pet Environ Biotechnol 6: 221. doi:10.4172/2157-7463.1000221

Page 6 of 7

\begin{tabular}{|c|c|c|c|c|c|}
\hline$F w$ & $\mu \mathrm{o} / \mu \mathrm{w}$ & Ŝw & $f w \mid s w f$ & Swf & $\hat{S} w-S w f$ \\
\hline$f w 1$ & 1 & 0.73 & 0.88 & 0.66 & 0.1 \\
\hline$f w 2$ & 5 & 0.61 & 0.8 & 0.53 & 0.1 \\
\hline$f w 3$ & 10 & 0.56 & 0.72 & 0.46 & 0.1 \\
\hline$f w 4$ & 15 & 0.52 & 0.7 & 0.42 & 0.1 \\
\hline$f w 5$ & 20 & 0.49 & 0.68 & 0.39 & 0.1 \\
\hline$f w 6$ & 25 & 0.47 & 0.6 & 0.36 & 0.1 \\
\hline$f w 7$ & 30 & 0.44 & 0.58 & 0.35 & 0.1 \\
\hline$f w 8$ & 35 & 0.43 & 0.58 & 0.34 & 0.1 \\
\hline$f w 9$ & 40 & 0.42 & 0.58 & 0.33 & 0.1 \\
\hline$f w 10$ & 45 & 0.41 & 0.58 & 0.32 & 0.1 \\
\hline$f w 11$ & 50 & 0.4 & 0.58 & 0.32 & 0.1 \\
\hline$f^{\prime} w 12$ & 100 & 0.35 & 0.58 & 0.29 & 0.1 \\
\hline
\end{tabular}

Table 1: Viscosity ratio and fractional flow characteristics.

\begin{tabular}{|c|c|c|}
\hline $\boldsymbol{S}_{w}$ & $\boldsymbol{k}_{\text {rw }}$ & 0 \\
\hline 0.2 & 0.002 & 0.8 \\
\hline 0.25 & 0.009 & 0.61 \\
\hline 0.3 & 0.02 & 0.47 \\
\hline 0.35 & 0.033 & 0.37 \\
\hline 0.4 & 0.051 & 0.285 \\
\hline 0.45 & 0.075 & 0.15 \\
\hline 0.5 & 0.1 & \\
\hline 0.55 & 0.132 & \\
\hline 0.6 & 0.17 & \\
\hline 0.65 & 0.208 & \\
\hline 0.7 & 0.251 & 0.095 \\
\hline 0.75 & 0.3 & \\
\hline 0.8 & 0.03 & \\
\hline
\end{tabular}

Table 2: Selected relative permeability and water saturation data.

Average Water Saturation

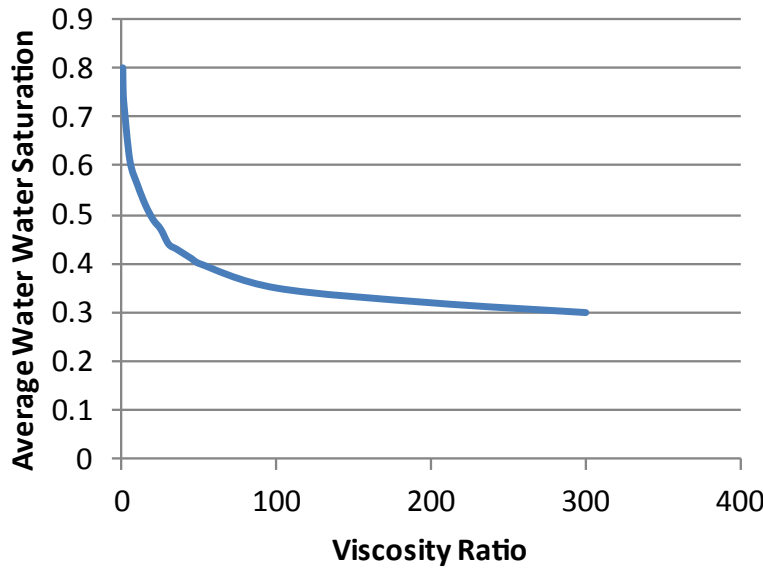

Average Water

Saturation

Figure 5: Relationship between $\bar{S}_{w}$ and $\frac{\mu_{o}}{\mu_{w}}$

the difference between the values of both at a specific viscosity ratio remains constant at all increases in the viscosity ratio. This fact is presented in Figure 8.

\section{Conclusion}

By the theoretical analysis of viscosity effects on water flooding performance, we come to the following conclusions. Optimum recovery is achieved at a viscosity ratio of 0.4 where the average water saturation equals the end point water saturation and any viscosity ratio less than this shows no significance as revealed on the fractional flow curve because all the movable oil has been produced. Viscous fluid appreciably improves oil recovery in reservoirs containing viscous oil. 
Citation: Mamudu A, Olalekan O, Uyi PG (2015) Analytical Study of Viscosity Effects on Waterflooding Performance to Predict Oil Recovery in a Linear System. J Pet Environ Biotechnol 6: 221. doi:10.4172/2157-7463.1000221

Page 7 of 7

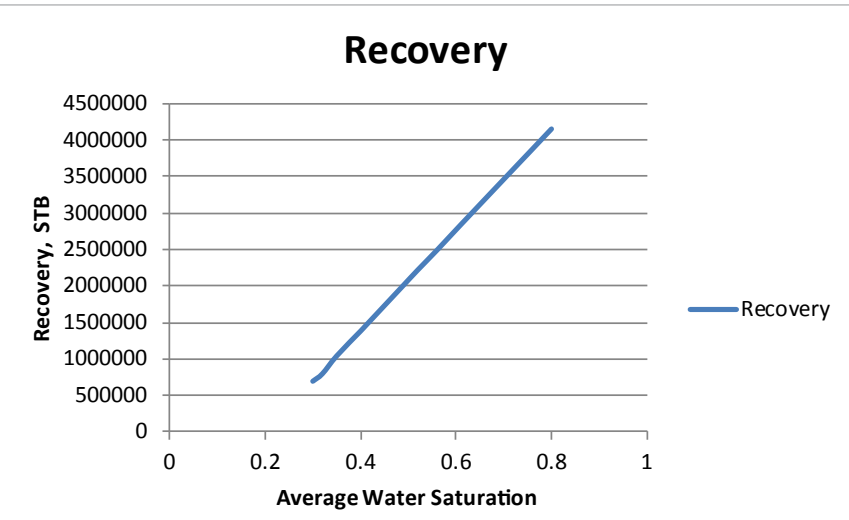

Figure 6: Linear Relationship Profile between $\bar{S}_{w}$ and $N_{p}$.

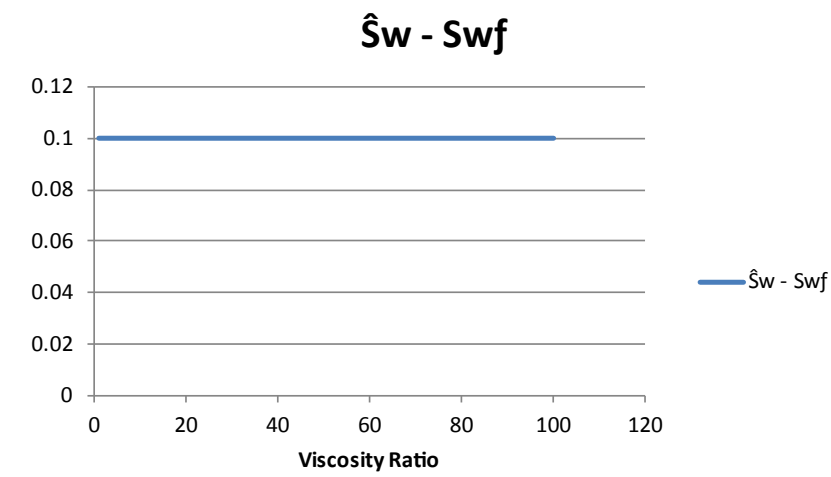

Figure 7: Constancy Profile of $\bar{S}_{w}-S_{w f}$

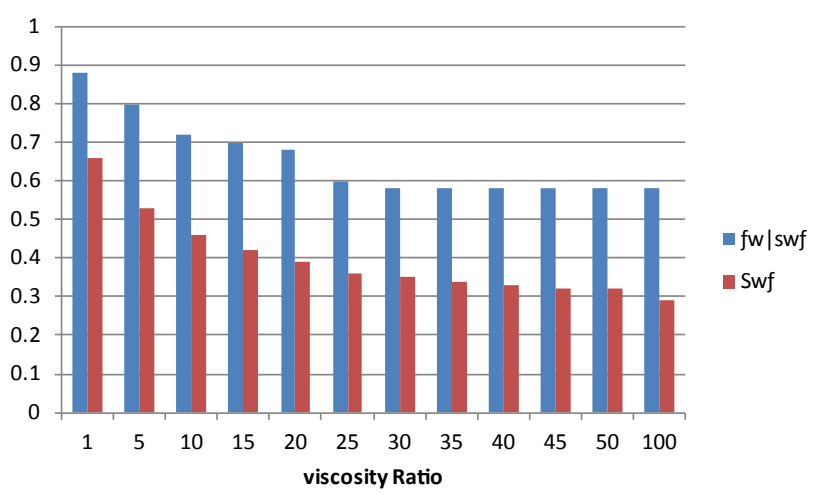

Figure 8: Comparative responses of $\left.f_{w}\right|_{S_{w f}}$ and $S_{w f}$ to viscosity ratio

Oil can still be recovered even at a viscosity ratio as high as 100. The nature of the s-shape of the fractional flow curve is directly dependent on the viscosity ratio. Efforts made to ensure that viscous water (fluid) is considered to maintain a viscosity ratio of 1 or less would be fruitful. The oil produced, $\left(N_{p}\right)$ and the average water saturation behind the shock front, $\left(\bar{S}_{w}\right)$ in an immiscible displacement system are linearly related. Recovery increases with decreasing viscosity ratio and decreases with increasing viscosity ratio.

\section{Acknowledgement}

This research was supervised and supported by the head of department of petroleum engineering, University of Benin, Benin City, Nigeria.

\section{References}

1. Don WG, Paul WG (1998) Enhanced Oil Recovery. Richardson, Texas, USA.

2. Willhits GP (1986) Waterflooding Textbook Series. SPE, Richardson, TX, USA

3. Amyx JW, Bass DM, Whiting RL (1986) Petroleum Reservoir Engineering. Mc Graw-Hill Book Co, New York City, USA.

4. Craig FF (1991) The Reservoir Engineering Aspects of Water Flooding, Monograph Series, SPE, Richardson, TX, USA.

5. Claridge EL, Bonder PL (1974) A Graphical Method for Calculating linear displacement with mass transfer and continuously Changing Mobility 14

6. Patton JT, Coast KH, Colegrove GT (1971) Prediction of Polymer Flood Performance. SPEJ 72-84, 11.

7. Pope GA (1980) The Application of Fractional Flow Theory to Enhanced Oi Recovery 20.

8. Welge HJA (1952) Simplified Method for Computing Oil Recoveries by Gas or Water Drive. Trans, AIME 195: 91-98.

9. Koval EJ (1963) A Method for Predicting the Performance of unstable miscible displacement in Heterogeneous media. SPEJ 145-54; Trans., AIME, 228.

10. Taber JJ (1969) Dynamic and Static Forces Required to Remove a Discontinuous Oil Phase from Porous Media containing both Oil and Water. SPEJ 3-12.

11. Dake LP (1998) Fundamentals of Reservoir Engineering.

12. Buckley SE, Leverett MC (1942) Mechanism of Fluid Displacement in Sand. trans., AIME: 146-116.

13. Tarek A, Pual DM (2005) Advanced Reservoir Engineering. 